\title{
Humanitarian Assistance and International Law (2018)
}

\author{
Dug Cubie*
}

\section{1 \\ Overview of Humanitarian Assistance in 2018}

An estimated 11.429 people died as a direct result of disasters during 2018, with over 96.700 people injured and nearly 60 million people affected. ${ }^{1}$ While the overall impact of storms and geophysical hazards, such as earthquakes and volcanoes, were lower than the long-term average, there was a sharp increase in fatalities arising from flooding - particularly in India, Japan, Nigeria and Kenya. ${ }^{2}$ Likewise, the second half of 2018 was marked by particularly severe wildfires in many parts of Europe and California, as well as tropical cyclones in the US and Japan. ${ }^{3}$ While local and national authorities and communities are typically the first responders to such events, ${ }^{4}$ international cooperation to assist affected states can play an important role in preventing and mitigating the human and financial impacts of natural and human-made hazards, and responding to disasters they may cause. ${ }^{5}$ Such international cooperation may take the form of bilateral and multilateral state-to-state assistance, as well as through the work of multilateral inter-governmental agencies, nongovernmental organisations, and the private sector.

Yet there is no single definition of "humanitarian assistance" in international law. Generally, humanitarian assistance is seen to encompass both the

* Lecturer, School of Law, University College Cork.

1 Figures from Centre for Research on the Epidemiology of Disasters, International Disaster Database (EM-DAT) <https://www.emdat.be/> last accessed (as any subsequent URL) on 2 September 2019.

2 Petra Löw, 'The Natural Disasters of 2018 in Figures', Munich Re (8 January 2019) <https:// www.munichre.com/topics-online/en/climate-change-and-natural-disasters/naturaldisasters/the-natural-disasters-of-2018-in-figures.html\#>.

3 Ibid.

4 For discussion of the role of local actors in the context of armed conflict, see: Steven Joe Dixon, Elsa Romera Moreno, Amal Sadozai and Ahmed Haj Asaad, 'Localisation of Humanitarian Response in the Syrian Crisis', (2016) 99 Confluences Méditerranée, 109-121 (also available in French).

5 For discussion of sociological understandings of disaster risk, see: Marie Aronsson-Storrier, 'Beyond Early Warning Systems: Querying the Relationship Between International Law and Disaster Risk (Reduction)', in this issue. 
material requirements necessary to sustain life, such as food, shelter and medical care, ${ }^{6}$ as well as the broader requirements for the protection of persons in humanitarian crises, including measures designed to ensure full respect for the rights of persons in need. ${ }^{7}$ In the context of international disaster law, Article 3 (e) of the International Law Commission (ILC) Draft Articles on the Protection of Persons in the Event of Disasters, defines 'external assistance' as: 'relief personnel, equipment and goods, and services provided to an affected State by an assisting State or other assisting actor for disaster relief assistance. ${ }^{8}$ Article 3 continues by defining 'relief personnel' as: 'civilian or military personnel sent by an assisting State or other assisting actor for the purpose of providing disaster relief assistance'; ${ }^{9}$ and 'equipment and goods' as: 'supplies, tools, machines, specially trained animals, foodstuffs, drinking water, medical supplies, means of shelter, clothing, bedding, vehicles, telecommunications equipment, and other objects for disaster relief assistance.'. ${ }^{10}$ As noted in the commentaries of the ILC Draft Articles, ${ }^{11}$ this formulation is based on both the UN Guidelines on The Use of Foreign Military and Civil Defence Assets in Disaster Relief ${ }^{12}$ and the 2000 Framework Convention on Civil Defence Assistance. ${ }^{13}$

Reflecting the extent of suffering arising from both armed conflicts and disasters, the Global Humanitarian Assistance Report 2018 estimated that during 2017 a total of 201.5 million people living in 134 countries were in need of such international humanitarian assistance. ${ }^{14}$ However, the report further noted that over 46 million of these people were living in just three countries (Yemen, Syria and Turkey). Consequently, while a total of US $\$ 27 \cdot 3$ billion was allocated

6 See, for example, Geneva Convention IV Relative to the Protection of Civilian Persons in Times of War, 12 August 1949, art. 23 and Protocol Additional to the Geneva Conventions of 12 August 1949, and relating to the Protection of Victims of International Armed Conflicts, 8 June 1977, art. 69 .

For discussion, see: Dug Cubie, The International Legal Protection of Persons in Humanitarian Crises: Exploring the Acquis Humanitaire (Hart Publishing 2017) 18-26.

The text and commentaries to the ILC's Draft Articles on the Protection of Persons in the Event of Disasters (adopted on second reading) are contained in: ILC 'Report of the International Law Commission on the work of its 68th Session' (2 May - 10 June and 4 July 12 August 2016), Supplement No.10, UN Doc A/71/10.

$9 \quad$ Ibid., art. $3(\mathrm{f})$.

$10 \quad$ Ibid., art. $3(\mathrm{~g})$.

11 Ibid., 9, para. 24.

12 OCHA, Guidelines on The Use of Foreign Military and Civil Defence Assets in Disaster Relief ('Oslo Guidelines') 2006, as revised on 1 November 2007.

13 ICDO, Framework Convention on Civil Defence Assistance, 22 May 2000.

14 Development Initiatives, Global Humanitarian Assistance Report 2018 (2018), 18. The Global Humanitarian Assistance Report has been running since 2000, and provides a detailed analysis of the preceding years' figures and trends in humanitarian assistance. 
globally to humanitarian activities, $60 \%$ of this assistance was directed to only 10 countries..$^{15}$ The difficulty in accurately classifying assistance provided for specific disaster events is evident by the fact that complex crises (involving at least two of: conflict, disasters associated with natural hazards, and refugee/ displacement situations) occurred in 29 of the 36 countries with the highest numbers of people in need. ${ }^{16}$ As one means of comparison, the International Federation of the Red Cross and Red Crescent Societies (IFRC), which deals with disasters, appealed for US $\$ 328$ million in funding during 2017; while the International Committee of the Red Cross (ICRC), which works primarily in armed conflict settings, appealed for US\$1.762 million in funding over the same period.

Meanwhile, the ALnAP State of the Humanitarian System 2018, covering the period $2015^{-17}$, noted mixed progress in the performance of humanitarian actors across a number of headings. ${ }^{17}$ For example, while the report noted an improvement in the effectiveness in meeting immediate life-saving needs in disasters, there was a decline in the sufficiency and coverage of humanitarian funding, and no progress in engaging local participation. ${ }^{18}$ The report noted a growth in humanitarian funding compared to 2015, and recorded an estimated 570.000 humanitarian personnel globally in 2017 - an increase of $27 \%$ compared to 2013. In particular, the report highlighted growth in national humanitarian staff, while the number of international staff remained stable. ${ }^{19}$

It is therefore clear that there is extensive practice by both State and NonState Actors in providing humanitarian funding, relief personnel, equipment, goods and services in both conflict and disaster settings. However, the distribution of such funding and activities is uneven, and is often driven by media coverage and political will. As highlighted by the Norwegian Refugee Council: 'Crises that are given little international attention and are seldom mentioned in the media, are also often declined the financial support needed to meet severe humanitarian needs.' ${ }^{20}$ As the 2018 Aurora Humanitarian Index of public perceptions in 12 diverse countries identified, $61 \%$ of respondents felt that they were suffering from 'crisis overload' and that there were too many humanitarian

\footnotetext{
$15 \quad$ Ibid., 13.

16 Ibid., 18.

17 ALNAP/ODI, State of the Humanitarian System 2018: Full Report (London ALNAP/ODI 2018).

18 Ibid., 24-27.

$19 \quad$ Ibid., 16.

20 Thale Jenssen, 'Why Some Crises are Neglected' (7 June 2018) Norwegian Refugee Council <https://www.nrc.no/news/2018/june/why-some-crises-are-neglected/>.
} 
crises to keep up with in the world today. ${ }^{21} 54 \%$ of respondents reported that they always hear the same stories and that coverage of issues such as refugees focuses on the same countries all the time..$^{22}$ In a similar manner, but from an operational perspective, CARE International's report on the 10 most underreported humanitarian crises of 2018 stressed:

The globe is scarred by violence and disasters. Climate change caused by fossil fuel emissions is hitting harder with every passing day. Yet, some crises receive less media coverage than others. Displacement in the Democratic Republic of Congo rivals that of Syria but has received far less attention. In the Central African Republic widespread starvation has set in, which has gone largely unnoticed. And while the catastrophic 2010 earthquake in Haiti hit the headlines, the food crisis in 2018 barely made international news. ${ }^{23}$

Moreover, seven out of the 10 humanitarian crises of 2018 examined by CARE International were in Africa, underscoring a clear regional imbalance in humanitarian funding and assistance. ${ }^{24}$ Such "forgotten" emergencies ${ }^{25}$ also starkly highlight the interconnected nature of armed conflict and disasters, alongside the increasingly evident role of climate change as a risk multiplier. ${ }^{26}$ Over the coming years, the threat to human life and livelihoods posed by the interplay of political instability and conflict with environmental and climactic hazards is only likely to increase. ${ }^{27}$ In recognition of the constantly changing

21 Aurora Humanitarian Initiative, 'Aurora Humanitarian Index 2018', $16<$ https://aurora prize.com/sites/all/themes/clives/versions/1/inc/image/ENG\%202018\%20Aurora\%20 Humanitarian\%2oIndex.pdf $>$. Based on over 10.000 interviews conducted in Argentina, Armenia, France, Germany, Iran, Japan, Kenya, Lebanon, Russia, Turkey, United Kingdom, and the United States of America, the annual global Index is intended to explore the international public's attitudes toward the responsibility and effectiveness of humanitarian intervention, as well as the motivations that urge people to intervene on behalf of others.

22 Ibid., 22.

23 CARE International, 'Suffering in Silence: The 10 Most Under-Reported Humanitarian Crises of 2018' (2019) 4 .

24 Ibid., 3.

25 See for example: Irish Aid, 'Ireland provides additional funding to forgotten humanitarian crises' (29 December 2017) Press Release <https://www.irishaid.ie/news-publications/ press/pressreleasearchive/2017/december/funding-forgotten-crises/>.

26 See, for example, the descriptions of the complex political and environmental crises in Chad, the Philippines and Madagascar. CARE International (n. 23).

27 See for example: Christopher B. Field et al, 'Managing the Risks of Extreme Events and Disasters to Advance Climate Change Adaptation', Special Report of the Intergovernmental Panel on Climate Change (CUP 2012). 
nature of humanitarian crises and operational requirements, the following section will examine some key issues in humanitarian policy and practice which occurred during 2018.

\section{Key Issues in Humanitarian Policy and Practice}

In February 2018, the London Times newspaper published an investigative report into Oxfam GB's humanitarian operations in Haiti. ${ }^{28}$ The Times alleged that Oxfam covered up an internal investigation into serious sexual exploitation by Oxfam staff in the aftermath of the Haitian earthquake of 2010, and allowed the Oxfam GB Haiti Country Director, Roland van Hauwermeiren, and two other staff members to resign, while also sacking four other staff members for gross misconduct. ${ }^{29}$ The immediate impact of the scandal led to the resignation of Oxfam's deputy chief executive and a sharp drop in public donations and funding; ${ }^{30}$ and both Archbishop Desmond Tutu and Minnie Driver withdrew their support as ambassadors for Oxfam. ${ }^{31}$ Following extensive media coverage of the Oxfam cover-up, other humanitarian organisations were also accused of ignoring or downplaying harassment and abuse by humanitarian workers. $^{32}$

By bringing to the fore the issue of the hiring policies of humanitarian organisations, as well as the safeguarding and response procedures to allegations

28 Sean O'Neill, 'Oxfam in Haiti: "It was like a Caligula orgy with prostitutes in Oxfam Tshirts"' The Times (London, 9 February 2018) <https://www.thetimes.co.uk/edition/news/ oxfam-in-haiti-it-was-like-a-caligula-orgy-with-prostitutes-in-oxfam-t-shirts-p32wlkorp>. Damien Gayle, 'Timeline: Oxfam sexual exploitation scandal in Haiti' The Guardian (Manchester, 15 June 2018) <https://www.theguardian.com/world/2018/jun/15/timeline -oxfam-sexual-exploitation-scandal-in-haiti>.

30 Shehab Khan, 'Oxfam to lay off 100 people as funding falls following aid worker sex scandal' The Independent (London, 18 May 2018) <https://www.independent.co.uk/news/uk/ home-news/oxfam-charity-lay-off-10o-people-haiti-sex-scandal-funding-cut-a 8357476 .html>.

$31 \quad$ Ibid.

32 See for example: Umberto Bacchi, 'More than 120 aid workers sacked, lost jobs over sexual misconduct in 2017 - survey' Thomason Reuters Foundation (London, 21 February 2018) $<$ https://www.reuters.com/article/us-britain-aid-harassment-exclusive/exclusive-more -than-120-aid-workers-sacked-lost-jobs-over-sexual-misconduct-in-2017-survey-idUSKCN $1 \mathrm{G}_{52} \mathrm{AE}>$; 'Now international aid organisation MSF says it had to sack 19 people for harassment last year' Agence France-Presse (15 February 2018) <https://www.thejournal.ie/msf -harassment-3852773-Feb2018/>; Rebecca Ratcliffe, “A boys' club”: UN agency accused over sexual harassment claims' The Guardian (Manchester, 25 February 2018) <https:// www.theguardian.com/global-development/2018/feb/24/un-former-employee-call-for -inquiry-sexism-bullying-harassment >. 
against aid workers, the response to the scandal reflected the broader \#MeToo Movement. ${ }^{33}$ In the immediate aftermath, the UN Inter-Agency Stand Committee's meeting on sexual exploitation and abuse (SEA) which was held on 15th March 2018 examined the question of humanitarian staff misconduct, and subsequently issued a paper entitled Preventing transgressors moving through the humanitarian system. ${ }^{34}$ The paper briefly sets out the procedures used by a selection of UN and other humanitarian organisations, and highlights the role of databases, pre-screening, self-declaration and consent provisions, and the verification of references. ${ }^{35} \mathrm{~A}$ subsequent joint strategy statement by the heads of UNICEF, UNHCR and OCHA identified three priority areas of action: (i) encouraging victims to come forward and a speak up culture; (ii) improving quality, survivor centred support and protection; and (iii) strengthened vetting, reference-checking, investigation processes and disciplinary measures. ${ }^{36}$

The majority of humanitarian staff are committed to protecting the rights of individuals and communities in which they work, and so the fundamental breach of trust which arises when some humanitarian workers abuse their position is particularly shocking. All moves to prevent such abuse, and punish those responsible, are therefore to be welcomed. However, the "endemic problem" of SEA in regards to UN peacekeeping missions highlights the difficulty in adequately addressing abuse by humanitarian personnel, ${ }^{37}$ and the on-going sector-wide responses to the cases identified in 2018 will need to be followed closely.

33 See for example:Molly Anders, 'Oxfam sexual abuse scandal:Are the aid sector's HR systems failing?' Devex (14 February 2018) <https://www.devex.com/news/oxfam-sexual-abusescandal-are-the-aid-sector-s-hr-systems-failing-92103>; Sheena McKenzie, 'Sexual abuse "endemic" in international aid sector, damning report finds' CNN (London, 31 July 218) $<$ https://edition.cnn.com/2018/07/30/uk/sexual-abuse-aid-sector-uk-report-intl/index .html>.

34 IASC, 'Preventing Transgressors Moving Through the Humanitarian System [Revision 1]' (31 May 2018) <https://interagencystandingcommittee.org/system/files/session_1-_psea -sha-_preventing_transgressors_moving_through_the_sector-31_may_2018-principals _meeting.pdf>.

35 Ibid., 7.

$36 \quad$ IASC, 'Strategy: Protection from and Response to Sexual Exploitation and Abuse and Sexual Harassment' (November 2018), issued by the IASC Champions on Sexual Exploitation, Abuse and Harassment and endorsed by IASC Principals on 3 December $2018<$ https:// interagencystandingcommittee.org/system/files/181101_iasc_champions_sea_sh_strate gy_final.pdf>.

37 Sabrina Karim and Kyle Beardsley, 'Explaining Sexual Exploitation and Abuse in Peacekeeping Missions: The Role of Female Peacekeepers and Gender Equality in Contributing Countries', (2016) 53(1) Journal of Peace Research, 100-115. 
In the wake of these scandals, the fourth edition of the Sphere Handbook: Humanitarian Charter and Minimum Standards in Humanitarian Response was published in November $2018 .^{38}$ Originally published in 2000 by a coalition of non-governmental humanitarian agencies and the Red Cross and Red Crescent Movement, over the past 20 years the Sphere Handbook has become a leading guide for humanitarian actors in both conflicts and disasters. ${ }^{39} \mathrm{Com}-$ mencing with the foundational principles, the Handbook is structured around the Humanitarian Charter, which encompasses the Protection Principles and Core Humanitarian Standard..$^{40}$ The Handbook then proceeds to elaborate a series of four technical standards for humanitarian assistance activities, covering: (i) Water Supply, Sanitation and Hygiene Promotion; (ii) Food Security and Nutrition; (iii) Shelter and Settlement; and (iv) Health.

The Humanitarian Charter, premised on the right of all persons affected by disasters and conflicts to receive protection and assistance to ensure the basic conditions for life with dignity, ${ }^{41}$ forms the legal and ethical backdrop to the rest of the Handbook. The Handbook acknowledges that it is a voluntary code for quality and accountability for humanitarian agencies, ${ }^{42}$ and so stresses that while the underlying principles are reflected in international law they derive their force ultimately from the fundamental moral principle of humanity. ${ }^{43}$ Noting, inter alia, an increase in complex and prolonged humanitarian crises, growing humanitarian needs in urban settings, and the diversification of humanitarian actors, the new edition contains a variety of additions to the 2011 edition of the Handbook. In particular, an emphasis is placed on supporting local action and community engagement, alongside new standards on cashbased assistance and supply chain management, clinical management of rape

38 Sphere Association, The Sphere Handbook: Humanitarian Charter and Minimum Standards in Humanitarian Response (4th ed, Geneva, Switzerland, 2018) < www.spherestan dards.org/handbook>.

39 As noted in the Introduction: 'The principal users of The Sphere Handbook are practitioners involved in planning, managing or implementing a humanitarian response (...) The Handbook is also used for humanitarian advocacy to improve the quality and accountability of assistance and protection in line with humanitarian principles'. Ibid., 4. For background regarding the development of the original Sphere Handbook, see: Peter Walker and Susan Purdin, 'Birthing Sphere', (2004) 28(2) Disasters, 100.

40 For discussion, see: Tommaso Natoli, 'Non-State Humanitarian Actors and Human Rights in Disaster Scenarios' in Flavia Zorzi Giustiniani, Emanuele Sommario, Federico Casolari and Giulio Bartolini (eds), Routledge Handbook of Human Rights and Disasters (Routledge 2018) 149, 156-158.

41 Sphere Handbook (n. 38) 5 .

42 Ibid., 8.

43 Ibid., 28. 
and sexual violence, and dealing with disease outbreaks in humanitarian crises. ${ }^{44}$

In September 2018, the UN Office for the Coordination of Humanitarian Affairs (OCHA) published their Recommended Practices for Effective Humanitarian Civil-Military Coordination of Foreign Military Assets (FMA) in Natural and Man-Made Disasters. ${ }^{45}$ As noted in the Introduction: 'The Practices were developed to capture decades of experience and lessons in humanitarian emergencies where humanitarian, military, and other governmental actors operate in the same geographic space, and in some circumstances, work together to address the needs of people affected by a crisis. ${ }^{46}$ Building on existing civilmilitary coordination approaches, such as the Oslo Guidelines, ${ }^{47}$ the Practices are intended to operationalise key principles and concepts, and to promote 'more principled, coherent, appropriate, and effective coordination' between different actors. ${ }^{48}$ Tracking the phases and integral components of military support to humanitarian action across five areas, namely preparedness, deployment, employment, transition, and monitoring and evaluation, the document notes:

Each context reflects unique operational constraints and considerations, including different binding legal regimes, and relevant stakeholders should discuss and identify which recommended Practices and approaches are relevant and appropriate for a particular emergency. ${ }^{49}$

The year concluded with OcHA's seventh annual Global Humanitarian Policy Forum (G HPF) which took place on 12 December 2018 under the theme of 'Solutions for Humanity: Creating opportunities for those furthest behind'. The Forum called for concrete ideas and solutions from participants on three key contemporary challenges, namely:

i. Ensuring respect for international humanitarian law in the delivery of humanitarian assistance;

44 Sphere Association, 'What is New?' brochure (no date) <https://spherestandards.org/wp -content/uploads/Sphere_Brochure_ENG_442X210_20181031_LR.pdf>.

45 оснA, Recommended Practices for Effective Humanitarian Civil-Military Coordination of Foreign Military Assets (FMA) in Natural and Man-Made Disasters (Version 1.o, 18 September 2018).

46 Ibid., 2.

47 OCHA (n. 12).

48 OCHA (n. 45) 2.

49 Ibid., 3. 
ii. Enabling more anticipatory, flexible and sustainable financing approaches to crisis contexts;

and

iii. How best to reduce need, risk and vulnerability by transcending humanitarian-development divides.

Following a public symposium and three thematic workshops comprised of humanitarian and developmental experts, four main issues were identified. ${ }^{50}$ First, the need for inclusive, sustainable development which actively involves the poorest and most marginalised, backed up by political commitment and solutions. Second, the need for leadership in increasing humanitarian finance, including funding which acknowledges the linkages between climate change, disasters and vulnerability. Third, the need to strengthen the humanitariandevelopment nexus and joined-up working; and finally that humanitarian access is a fundamental prerequisite for humanitarian action as clearly set out in international humanitarian law.

The Forum concluded with the launch of OcHA's Agenda for Humanity Annual Synthesis Report 2018. As the main outcome document of the 2016 World Humanitarian Summit, the UN's Agenda for Humanity sets out five major areas for action and change, called 'Core Responsibilities', that are needed to address and reduce humanitarian need, risk and vulnerability, alongside a series of targets and indicators (called "Transformations") for each core responsibility. While the first two core responsibilities relate specifically to armed conflict (prevent and end conflicts, and respect rules of war), the other three equally relate to disaster contexts (leave no one behind, work differently to end need, and invest in humanity). The Synthesis Report is compiled via self-reporting by $15^{2}$ stakeholders including states, UN agencies and nongovernmental organisations. ${ }^{51}$ While some progress was noted in regards to greater inter-agency cooperation and early action, as well as strengthening local and national capacities, the Report highlighted that progress had been uneven and 'mainly limited to what can be achieved within existing humanitarian systems. 52 Of particular note, stakeholders highlighted that the humanitarian sector's 'commitment and capacity to work towards gender

5о осна, 'Four Takeaways from the Humanitarian Policy Forum' (20 December 2018) $<$ https://medium.com/@UNOCHA/four-takeaways-from-the-humanitarian-policy -forum-b3c1icbo2bc8>.

51 оснA, 'Staying the Course: Delivering on the Ambition of the World Humanitarian Summit, Agenda for Humanity Annual Synthesis Report 2018' (Geneva 2018) 3.

Ibid., 2. 
equality and empower women and girls remains woefully inadequate. ${ }^{53}$ Clearly, more work is required to adequately protect all persons in humanitarian crises. Ensuring coherence between humanitarian policy and practice, and further development of international law relating to humanitarian assistance is therefore required.

$53 \quad$ Ibid., 9 . 